\title{
Detecting, mapping and monitoring of land subsidence in Jharia Coalfield, Jharkhand, India by spaceborne differential interferometric SAR, GPS and precision levelling techniques
}

\author{
R S Chatterjee ${ }^{1, *}$, Shailaja Thapa ${ }^{1}, \mathrm{~K}_{\text {B }} \mathrm{Singh}^{2}, \mathrm{G}_{\text {Varunakumar }}^{3}$ and E V R Raju ${ }^{4}$ \\ ${ }^{1}$ Indian Institute of Remote Sensing (Indian Space Research Organization), 4-Kalidas Road, \\ Dehradun 248 001, India. \\ ${ }^{2}$ CSIR - Central Institute of Mining and Fuel Research, Barwa Road, Dhanbad 826 001, India. \\ ${ }^{3}$ Geodetic and Research Branch (Survey of India), 17 E.C. Road, Dehradun 248 001, India. \\ ${ }^{4}$ Bharat Coking Coal Ltd. (Coal India Ltd.), Koyla Nagar, Dhanbad 826 005, India. \\ *Corresponding author.e-mail: rschatterjee@iirs.gov.in
}

\begin{abstract}
The study aims at detection, mapping and monitoring of land subsidence in Jharia Coalfield, Jharkhand, India by spaceborne DInSAR, GPS and precision levelling techniques. Using multi-frequency C- and L-band DInSAR, both slowly and rapidly subsiding areas were identified and DInSAR-based subsidence maps were prepared. C-band DInSAR was found useful for detection of slowly subsiding areas whereas L-band DInSAR for rapidly subsiding and/or adverse land cover areas. Due to dynamic nature of mining and adverse land cover, temporal decorrelation poses a serious problem particularly in C-band DInSAR. Specially designed InSAR coherence guided adaptive filtering was found useful to highlight the deformation fringes. Collateral GPS and levelling observations were conducted in three test sites to validate DInSAR measurements and to determine the net displacement vectors. We observed an appreciable horizontal displacement component of land subsidence in all the test sites. For comparison of results, we calculated InSAR coherence weighted LOS displacement rates from the unwrapped differential interferograms of smaller spatial subsets and LOS projected ground-based displacement rates in three test sites. We found good agreement between DInSAR and ground-based measurements except for C-band observation in Dobari test site primarily due to large difference in observation periods and temporally inconsistent land subsidence. Collateral spaceborne and ground-based observations were also found useful for characterization of subsidence phenomena to determine net displacement vector and horizontal displacement component. In coal mining areas with spatially scattered and temporally irregular land subsidence phenomena, the adopted methodology can be used successfully for detection, mapping and monitoring of the subsiding areas vulnerable to future collapse. This will facilitate efficient planning and designing of surface infrastructures and other developmental structures in the mining areas and mitigation management of subsidence induced hazards.
\end{abstract}

\section{Introduction}

In a coalfield, land subsidence poses constant threats to life and surface infrastructures such as motor roads, railway tracks, power lines and other developmental structures. The present study was carried out in Jharia Coalfield, Jharkhand, India.

Keywords. Land subsidence; coal mining area; spaceborne DInSAR; GPS observation; precision levelling; net displacement; Jharia Coalfield; India. 
This is one of the most important and oldest coalfields in the country. This is the only source of prime coking coal in India with a reserve of about 5.3 billion tons (Acharyya 2000) in addition to large quantities of medium and semi-coking coals. Land subsidence and associated roof collapse is one of the major environmental hazards in the coalfield. Precise information on the spatial extent of subsiding areas and the rate of subsidence may help in identifying the areas prone to roof collapse in the near-future and in planning of the rehabilitation programme. In this paper, we have studied land subsidence by spaceborne DInSAR, GPS and precision levelling techniques. Spaceborne DInSAR provides spatially continuous displacement measurements at centimetre to sub-centimetre level precision with ground resolution of a few tens of metres. High precision GPS observations provide point-based displacement measurements at a precision comparable to DInSAR technique. Precision levelling is a slow and labour-intensive technique, but it provides amazingly high precision of submillimetre (height resolution) and millimetre (distance resolution) levels with the presently available digital level (Chatterjee 2009).

Many previous researchers conducted land subsidence studies in coal mining areas by single frequency DInSAR technique using either C- or L-band SAR data (Stow and Wright 1997; Perski 1998, 2000; Strozzi et al. 2001; Perski and Jura 2003; Engelbrecht et al. 2011; Gong 2011). Some conducted multi-frequency DInSAR using both C- and L-band SAR data (Ge et al. 2007; Cao et al. 2008; Liu et al. 2009; Yue et al. 2011). Some studies were also carried out using recently available spaceborne X-band SAR data (e.g., TerraSAR-X, Cosmo-Skymed SAR data) along with C- and Lband SAR data (Walter et al. 2009; Ashrafianfar et al. 2011). In coal mining areas, the causes of land subsidence are generally complex and spatially varied. This gives rise to spatially scattered, patchy and irregular subsidence fringes (Stow and Wright 1997; Perski 1998; Perski and Jura 2003). Moreover, the rates of subsidence may vary from a few centimetres to more than a metre per year in different parts of the coalfield and many a time are temporally inconsistent. In the case of C-band DInSAR using the data from ERS, ENVISAT and RADARSAT satellites with standard revisit time of 35 days and 24 days respectively, the temporal decorrelation of the data pairs appears to be a serious concern for DInSAR feasibility. In C-band DInSAR, the data pairs need to be much more restricted in terms of spatial and temporal baselines than L-band DInSAR (Liu et al. 2009). The fringe centres in C-band DInSAR sometimes lose information due to temporal decorrelation (Yue et al. 2011). However, C-band DInSAR is more sensitive to slow deformation and is therefore better suited for slow velocity subsidence measurements using shorter temporal baseline data pairs. On the other hand, L-band DInSAR has the advantage for detecting high velocity deformation gradient due to its longer wavelength. Also, the InSAR coherence in L-band remains generally high for a longer temporal baseline data pair which enables to produce meaningful differential interferograms for a longer time span (Yue et al. 2011). In coal mining areas with unfavourable land use/land covers such as vegetation covered areas (Wang et al. 2010) or rural areas with agricultural practices (Cao et al. 2008), L-band DInSAR proves to be more suitable for land subsidence study.

We carried out multi-frequency DInSAR measurements using C- and L-band SAR data to study both slow and rapid deformation areas. In the context of the present study area, the term 'slow' means a few centimetres to a few tens of centimetres per year and 'rapid' means a few tens of centimetres to more than a metre per year. By spaceborne DInSAR technique, we measured land subsidence along the radar line of sight (LOS). We conducted precision levelling in three test sites during 20072008. Levelling gives point-based measurements on vertical displacement of the terrain at millimetre level precision. We also conducted geodetic GPS survey over the test sites to precisely measure horizontal displacements. GPS observation gives sub-centimetre level of horizontal precision. We used levelling and GPS measurements to validate DInSAR-based subsidence rates and to determine the net displacement vectors.

\section{Study area}

The study area Jharia Coalfield lies between latitudes $23^{\circ} 35^{\prime}-23^{\circ} 55^{\prime}$ and longitudes $86^{\circ} 05^{\prime}-86^{\circ} 30^{\prime}$. It is located in the Dhanbad district of Jharkhand state, India at a distance of about $250 \mathrm{~km}$ NW of Kolkata City and covering an area of $450 \mathrm{~km}^{2}$ approximately (figure 1). This is one among the 54 Permo-Carboniferous Gondwana coalfields in India. Gondwana coalfields are known for high quality and large reserve of coal in India.

In the study area, land subsidence occurs primarily due to underground mining and subsurface coal fire. The source causes namely different types of underground mining (e.g., bord-and-pillar, longwall mining, depillaring and caving), water logging of the abandoned underground mine workings (or galleries) and subsurface coal fire, are diverse in nature and spatio-temporally haphazard. This gives rise to irregular and complex deformation 

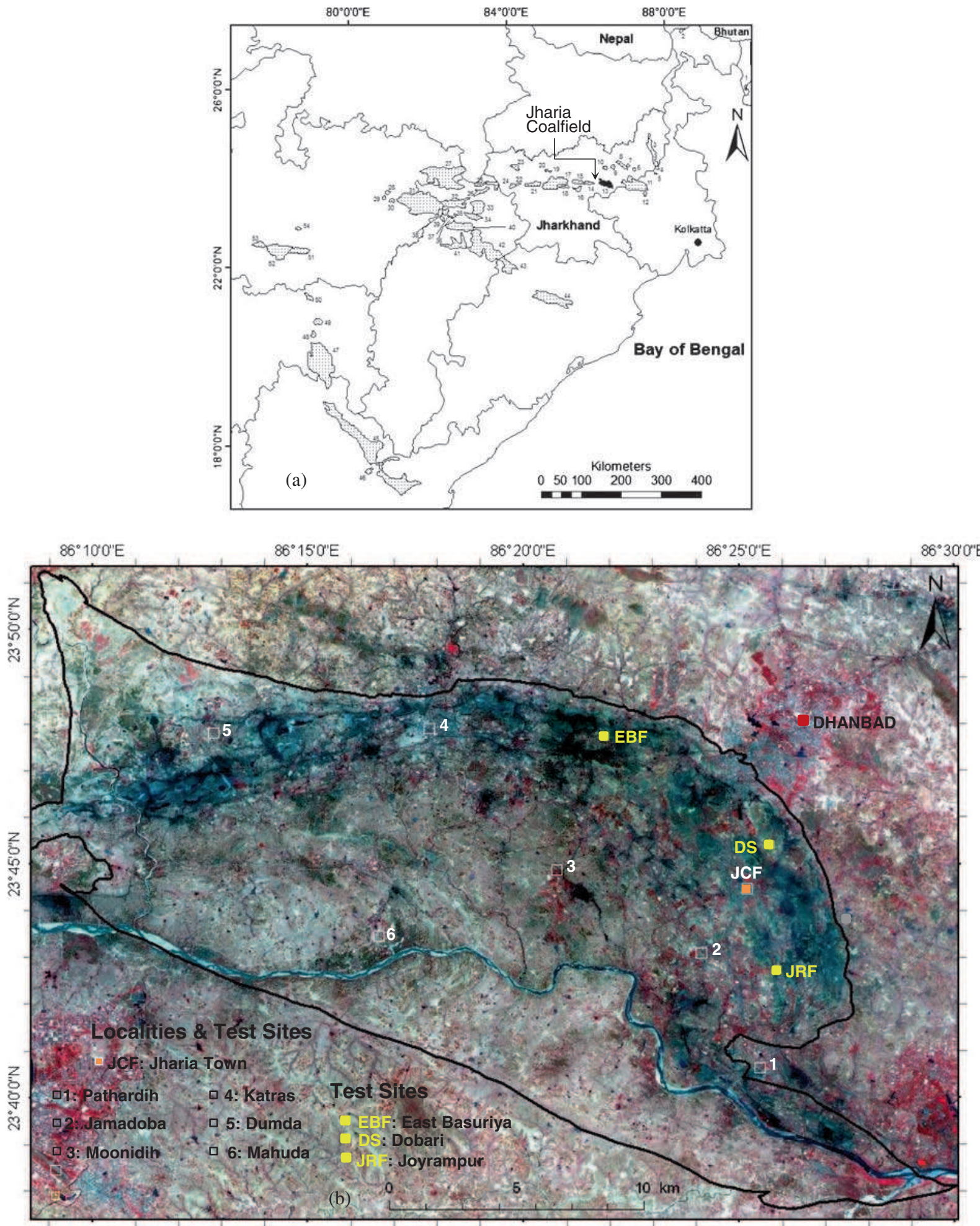

Figure 1. Location of the study area: Jharia Coalfield in Jharkhand state of India (a) (after Acharyya 2000). The coalfield is seen on PAN-sharpened IRS LISS-3 standard FCC 432 (R-G-B) image product (b). Test sites for ground-based land subsidence measurements by precision levelling and GPS survey are shown in (b).

pattern. Depillaring by caving of the existing galleries is generally responsible for rapid land subsidence phenomena. Caving is mostly carried out in virgin areas. On the other hand, depillaring accompanied by sand stowing is done in the settlement areas. It does not cause significant land subsidence.
Moreover, many unknown and unmapped abandoned galleries (underground mine workings) exist in the coalfield as a bi-product of private mining during pre-nationalization period. Water logging of the abandoned galleries can lead to land subsidence and roof collapse. Similarly, sub-surface coal fire 
can also lead to land subsidence and roof collapse. The Jharia Coalfield is known for hosting the highest number of coal fires among all the coalfields in India. The subsurface coal fires occur mostly at shallow depth $(<40 \mathrm{~m})$ (Mukherjee et al. 1991). They consume coal from the seams and produce huge voids which lead to surface cracks and land subsidence. Moreover, the lateral propagation of coal fire (Chatterjee 2006) causes spatially dynamic land subsidence phenomena. The Jharia town with a population of about 82,000 (Census of India 2001) has been experiencing the danger of coal fire and land subsidence due to intensive mining operations (Lokhande et al. 2008) and subsurface coal fire (Chatterjee 2006). Beside Jharia town, many other areas in the coalfield are also affected by land subsidence. Many of them are located near settlement areas. Many of the affected areas remain unreported due to slow subsidence rates and less significant surface effects. A high precision spatially-continuous measurement on land subsidence can facilitate identification of those affected areas that are vulnerable to future roof collapse.

In Jharia Coalfield, coal mining is done by three agencies: Bharat Coking Coal Ltd (BCCL) of Coal India Ltd., Tata Steel and Steel Authority of India Ltd. (SAIL). We procured the surface plans of 2006-2008 from the three agencies which vary in scale from 1:2000 to 1:16,000. We extracted subsidence-related degraded lands resulting from mining and coal fire from the individual surface plans (figure 2). From the surface plans, we found the total degraded lands of $23.9 \mathrm{~km}^{2}$. Out of which mining induced subsidence affected areas comprise $7.0 \mathrm{~km}^{2}$, whereas coal fire and fire induced subsidence areas comprise $16.9 \mathrm{~km}^{2}$. Because, surface plans are generally updated in areas of active mining operations and therefore many of the mininginduced subsidence areas occurring above old and abandoned underground mines were not reported in the surface plans.

\section{Materials and methods}

\subsection{Datasets}

\subsubsection{Spaceborne SAR Data}

Six pairs of ENVISAT ASAR C-band (wavelength $5.6 \mathrm{~cm}$ ) single look complex (SLC) images acquired during 2003-2007 were used for DInSAR processing (table 1). C-band InSAR data are highly sensitive to slowly subsiding areas because of their shorter wavelength. The data were acquired in narrow swath IS2 beam (off-nadir look angle: $19.2-26.7^{\circ}$ with a mean look angle $23^{\circ}$ approximately), VV-polarization and descending orbit. Four ENVISAT ASAR scenes were acquired during 2003-2004 and five scenes were acquired during 2007. InSAR data pairs were selected primarily based on spatial and temporal baselines of the pairs and seasonal criteria to ensure the minimum possible geometric and temporal decorrelations. The data pairs with shorter spatial baselines were preferred as they have lesser geometric decorrelation and topographic sensitivity. The data acquired during dry season of the year (OctoberMay) were preferred to ensure lesser temporal decorrelation due to seasonal changes of the land cover and dielectric properties of the surface materials. In addition, the Doppler difference between master and slave images of the data pairs was also considered to be an important factor. The SAR image pairs with a large Doppler difference are not appropriate for interferometric processing because they do not overlap their spectrum, causing coherence loss. So, the data pairs with low Doppler difference were procured. Standard orbit state vectors obtained from the onboard DORIS instrument are available with the ENVISAT ASAR data products. We used the most precise orbit state vectors (Verified Orbits or VOR version of orbit data) obtained from DORIS data processed on the ground.

Similarly, six pairs of ALOS PALSAR L-band (wavelength $23.62 \mathrm{~cm}$ ) SLC images acquired during 2007-2008 were used for DInSAR processing (table 1). L-band InSAR data were used essentially to overcome the problem of temporal decorrelation noise in C-band data and to address rapidly subsiding areas where the deformation gradient exceeds the limit for DInSAR measurements in Cband data. The data pairs were acquired in fine beam single (FBS) polarization (HH-polarization), ascending orbit with mean off-nadir look angle $34.3^{\circ}$ (table 1). The criteria for data selection were similar to that of C-band data as described above. However, due to lesser geometric restriction and temporal decorrelation problem in longer wavelength L-band data, the data pairs with larger spatial and temporal baselines than C-band data could be used for DInSAR processing. We used the most precise orbit state vectors available with ALOS PALSAR data products. Precise orbit state vectors were determined using global and high accuracy trajectory determination system and the evaluation of the orbit determination accuracy by SLR data (Nakamura et al. 2007).

\subsubsection{Digital elevation model (DEM)}

A high quality DEM of the study area with $10 \mathrm{~m} \times$ $10 \mathrm{~m}$ pixels and a vertical accuracy of approximately $8 \mathrm{~m}(8.1 \mathrm{~m})$ was generated from Cartosat-1 optical stereoscopic data pair of April 2006 (spatial resolution of Cartosat-1 data is $2.5 \mathrm{~m}$ ). Shuttle 


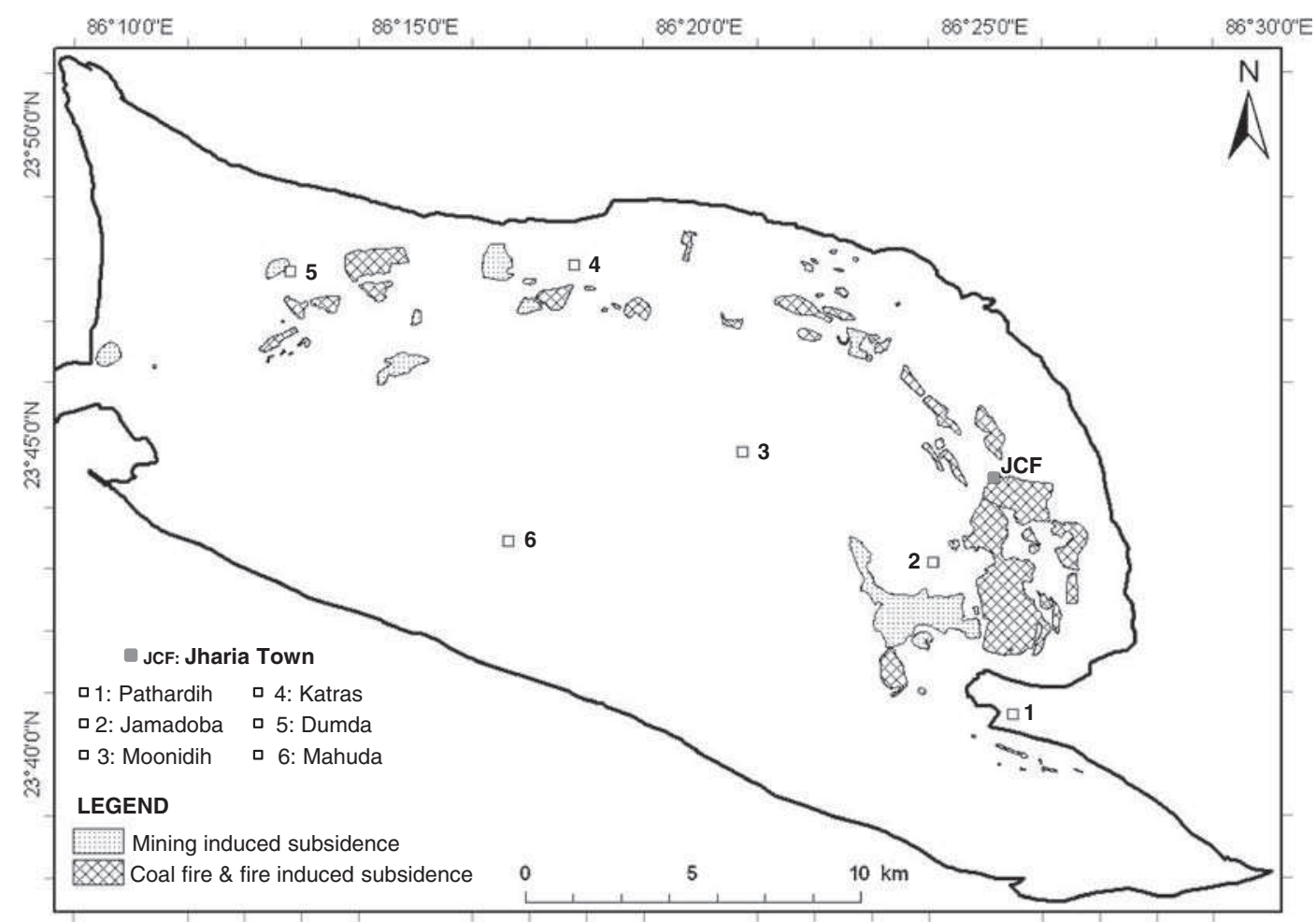

Figure 2. Spatial disposition of degraded lands consisting of mining-induced subsidence, coal fire and fire-induced subsidence areas as shown in large scale surface plans (1:2000-1:16000 scale) by the mining agencies (BCCL, Tata Steel, SAIL) based on ground surveying (survey period: 2006-2008).

radar topography mission (SRTM) coarse resolution DEM (SRTM-3) does not have the required horizontal and vertical precisions. Also, it gives a few years old DEM (dated February 2000) which is not appropriate to compensate topographic phase from the InSAR data pairs of 2007-2008 for a dynamic terrain like the present study area. On the other hand, Cartosat-1 has a limited swath of $25 \mathrm{~km}$. We used Cartosat-1 DEM for the core study area and SRTM $3 \times 3$ arc-sec (SRTM-3) coarse resolution DEM with $90 \mathrm{~m}$ spatial resolution for the surrounding areas outside Cartosat DEM as required for DInSAR processing of SAR data covering the study area.

\subsection{Measurement techniques and methodology}

\subsubsection{DInSAR processing and analysis}

In InSAR processing, we initially assessed the feasibility of the data pairs for DInSAR. From the good data pairs, we generated raw interferograms. We used a high precision external DEM (as mentioned above) for improved co-registration of master and slave images and for topographic phase removal in DInSAR processing. Flat-earth and topographic phase components were removed simultaneously from the raw interferometric phase using InSAR geometry of the data pair and external DEM.
Topography compensated InSAR coherence images were generated and average scene coherence of the study area for all the data pairs (table 1) was retrieved. After flat-earth and topographic phase removal, the differential interferograms contain deformation phase, differential atmospheric phase and temporal terrain decorrelation noise. The interferograms are noisy due to high temporalterrain decorrelation noise which occurred due to wavelength-scale disturbance of the ground surface resulting from intense land surface changes and surface fracturing associated with mining operations, unfavourable land use/land cover in and around the mining areas (unorganized hutments and vegetation cover adjacent to old mine workings) and agricultural practices in rural areas. We applied adaptive filtering by coherence guided approach (Goldstein and Werner 1998) to suppress noise and to highlight the deformation fringes (Chatterjee et al. 2006). Filtering was done in increments and over smaller moving windows to preserve local phase information of the deformation fringes. We identified the deformation fringes from filtered differential interferograms, analyzed them manually and validated on the ground and/or with the large-scale surface plans of the mining agencies (BCCL, Tata Steel and SAIL). To obtain the rates of subsidence, we manually retrieved the maximum phase difference in the deformation fringes 


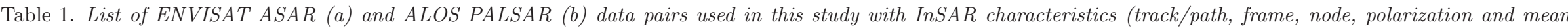
off-nadir look angle of the scenes are given below the table).

\begin{tabular}{|c|c|c|c|c|c|c|c|c|}
\hline \multicolumn{9}{|c|}{ (a) ENVISAT DInSAR data pairs } \\
\hline \multirow{2}{*}{$\begin{array}{l}\text { Sl. } \\
\text { no. }\end{array}$} & \multirow{2}{*}{$\begin{array}{c}\text { Data pair } \\
\text { (with orbit no.) }\end{array}$} & \multicolumn{2}{|c|}{ Date of pass (yyyy/mm/dd) } & \multirow[b]{2}{*}{$\Delta \mathrm{t}$ (days) } & \multirow{2}{*}{$\begin{array}{l}\mathrm{B}_{\perp}(\mathrm{m})(\text { Critical } \approx 930 \mathrm{~m}) \\
\left.\text { (altitude of ambiguity, } \mathrm{H}_{\mathrm{a}}\right)\end{array}$} & \multirow[b]{2}{*}{ Season } & \multirow{2}{*}{$\begin{array}{l}\text { Doppler shift }(\mathrm{Hz}) \\
(\text { critical } \approx 1650 \mathrm{~Hz})\end{array}$} & \multirow{2}{*}{$\begin{array}{c}\text { Average scene coherence } \\
\text { of the study area }\end{array}$} \\
\hline & & Master scene $^{\mathrm{P}}$ & Slave scene $\mathrm{p}^{\mathrm{p}}$ & & & & & \\
\hline 1 & C8833-9334 & $2003 / 11 / 08$ & $2003 / 12 / 13$ & 35 & $75.675(125.017)$ & Dry-dry & -54.138 & $0.29 \pm 0.15$ \\
\hline 2 & C9334-11338 & $2003 / 12 / 13$ & $2004 / 05 / 01$ & 140 & $278.42(37.98)$ & Dry-dry & -1.740 & $0.23 \pm 0.12$ \\
\hline 3 & C9835-11338 & $2004 / 01 / 17$ & $2004 / 05 / 01$ & 105 & $234.808(40.291)$ & Dry-dry & -9.930 & $0.26 \pm 0.14$ \\
\hline 4 & C26368-26869 & $2007 / 03 / 17$ & $2007 / 04 / 21$ & 35 & $265.75(35.56)$ & Dry-dry & 8.526 & $0.28 \pm 0.13$ \\
\hline 5 & C26368-27370 & $2007 / 03 / 17$ & $2007 / 05 / 26$ & 70 & $309.22(30.595)$ & Dry-dry & 12.917 & $0.25 \pm 0.13$ \\
\hline 6 & C29374-30376 & $2007 / 10 / 13$ & $2007 / 12 / 22$ & 70 & $159.02(59.494)$ & Dry-dry & 3.180 & $0.23 \pm 0.13$ \\
\hline \multicolumn{9}{|c|}{ (b) ALOS PALSAR DInSAR data pairs } \\
\hline \multirow{2}{*}{ S } & & \multicolumn{2}{|c|}{ Date of pass (yy/mm/dd) } & & \multirow{2}{*}{$\begin{array}{l}\mathrm{B}_{\perp}(\mathrm{m})(\text { critical } \approx 13050 \mathrm{~m}) \\
\left.\text { (altitude of ambiguity, } \mathrm{H}_{\mathrm{a}}\right)\end{array}$} & \multirow[b]{2}{*}{ Season } & \multirow{2}{*}{$\begin{array}{l}\text { Doppler shift }(\mathrm{Hz}) \\
(\text { critical } \approx 2160 \mathrm{~Hz})\end{array}$} & \multirow{2}{*}{$\begin{array}{c}\text { Average scene coherence } \\
\text { of the study area }\end{array}$} \\
\hline & Data pair & Master scene $^{\mathrm{q}}$ & Slave scene ${ }^{\mathrm{q}}$ & $\Delta \mathrm{t}$ (days) & & & & \\
\hline 1 & C5421-10118 & $2007 / 01 / 30$ & $2007 / 12 / 18$ & 322 & $1322.037(48.433)$ & Dry-dry & -8.432 & $0.25 \pm 0.11$ \\
\hline 2 & C5421-10789 & $2007 / 01 / 30$ & $2008 / 02 / 02$ & 368 & $1853.132(34.553)$ & Dry-dry & -10.503 & $0.24 \pm 0.11$ \\
\hline 3 & C5421-11460 & $2007 / 01 / 30$ & $2008 / 03 / 19$ & 414 & $1679.330(38.129)$ & Dry-dry & -15.309 & $0.21 \pm 0.11$ \\
\hline 4 & C10118-10789 & $2007 / 12 / 18$ & $2008 / 02 / 02$ & 46 & $534.585(119.796)$ & Dry-dry & -2.071 & $0.53 \pm 0.15$ \\
\hline 5 & C10118-11460 & $2007 / 12 / 18$ & 2008/03/19 & 92 & $357.273(179.251)$ & Dry-dry & -6.877 & $0.45 \pm 0.14$ \\
\hline 6 & C10789-11460 & $2008 / 02 / 02$ & $2008 / 03 / 19$ & 46 & $179.666(356.316)$ & Dry-dry & -4.806 & $0.53 \pm 0.14$ \\
\hline
\end{tabular}

PTrack: 411, frame: 3123 , node: descending, polarization: VV, mean off-nadir look angle: $23^{\circ}$.

"Path: 510, frame: 460, node: ascending, polarization: $\mathrm{HH}$, mean off-nadir look angle: $34.3^{\circ}$. 
followed by their conversion to radar line-of-sight (LOS) surface displacement.

For the three test sites with ground-based observations, we processed the data pairs in smaller spatial subsets covering the deformation fringes, in and around the respective test sites. As InSAR coherence values of the smaller subsets are reasonably high, phase unwrapping could be done. We performed phase unwrapping by 'Region Growing' or 'Minimum Cost Flow' algorithm for average InSAR coherence $\geq 0.4$ and $<0.4$, respectively. From each of the unwrapped differential interferograms, we retrieved the maximum deformation phase in the regions of interest, in and around the ground observation monuments and calculated radar LOS displacement rates. The quality of DInSAR phase values and its contribution in the determination of DInSAR-based subsidence rate is essentially controlled by InSAR coherence of the respective data pairs. So, we calculated InSAR coherence weighed LOS displacement rates for three test sites to compare with ground-based measurements.

\subsubsection{Precision levelling}

Precision levelling was conducted for measuring vertical movement (rise or fall) with respect to Bench Mark (BM). A detailed account on levelling survey for land subsidence monitoring is available in Tosi et al. (2007). We conducted multi-date precision levelling survey in three test sites namely Dobari, Joyrampur and East Basuriya collieries for studying underground mining and/or coal fire induced land subsidence (figure 1c). Precision levelling survey was conducted along multiple transects with a common observation point. In each test site, we placed 10-25 subsidence monitoring stations (or monuments) at an interval of approximately $25 \mathrm{~m}$. We used the presently-available, high-end digital level which carries out measurements electronically and provides height resolution up to $0.01 \mathrm{~mm}$ and distance resolution up to $1 \mathrm{~mm}$ (Trimble 2007). Levelling was conducted four times during the observation period such as in January 2007, April 2007, October 2007 and June 2008. The height differences of the monuments in successive levelling surveys were calculated to obtain the vertical displacement rates of the terrain at monument locations. Subsequently, for each test site, the average vertical displacement rate during the observation period was determined.

\subsubsection{GPS observation}

In GPS survey, carrier phase based dual frequency GPS receivers (Trimble 5700) were used and classical static survey was adopted for achieving millimetre level positioning accuracy (Leick 2004). From multi-epoch GPS observations, the changes in horizontal coordinates of the monuments were calculated to obtain lateral movement of land surface (horizontal displacement). We conducted GPS survey in three test sites (figure 1c) with 10-25 monuments where precision levelling was also conducted. Three independent GPS surveys were conducted namely in July 2006, April 2007 and June 2008. Three GPS receivers were used simultaneously to carry out survey in triangulation mode (keeping one at the base station). The duration for data reception in each session was set at 30-35 min, with an epoch interval of $30 \mathrm{~s}$ and an elevation mask of $15^{\circ}$. GPS data were collected during good GPS satellite constellation when the geometric dilution of precision (GDOP) was less than 4 . GPS data processing was done by TGO (Trimble Geomatics Office) software in triangulation mode with respect to a reference station which is located in a relatively unaffected place in the neighbourhood. The coordinate of the reference point was computed with respect to an existing control point of Survey of India.

\section{Results and discussion}

\subsection{DInSAR results}

In C-band differential interferograms generated from six pairs of ENVISAT ASAR data, we observed deformation fringes at multiple locations of the coalfield. In InSAR coherence-guided, filtered interferograms, the deformation fringes are highlighted (figure 3). From the filtered differential interferograms and ground information, Cband DInSAR-based land subsidence maps were prepared (figures 4-6). From the unwrapped differential interferograms of smaller spatial subsets, InSAR coherence weighed LOS displacement rates were determined for the three test sites (table 2).

Similarly, in L-band differential interferograms generated from six pairs of ALOS PALSAR data, the deformation fringes were observed at various locations. The deformation fringes are much more clear and prominent in L-band DInSAR (figure 3) compared to that in C-band. From the filtered differential interferograms and ground information, L-band DInSAR-based land subsidence maps were prepared (figures 5 and 6). Subsequently for three test sites, InSAR coherence weighed LOS displacement rates were determined from the unwrapped differential interferograms (table 2).

We found many new subsidence areas in the differential interferograms that are neither reported earlier nor shown in the surface plans. In such areas, we observed definitive evidences of land 

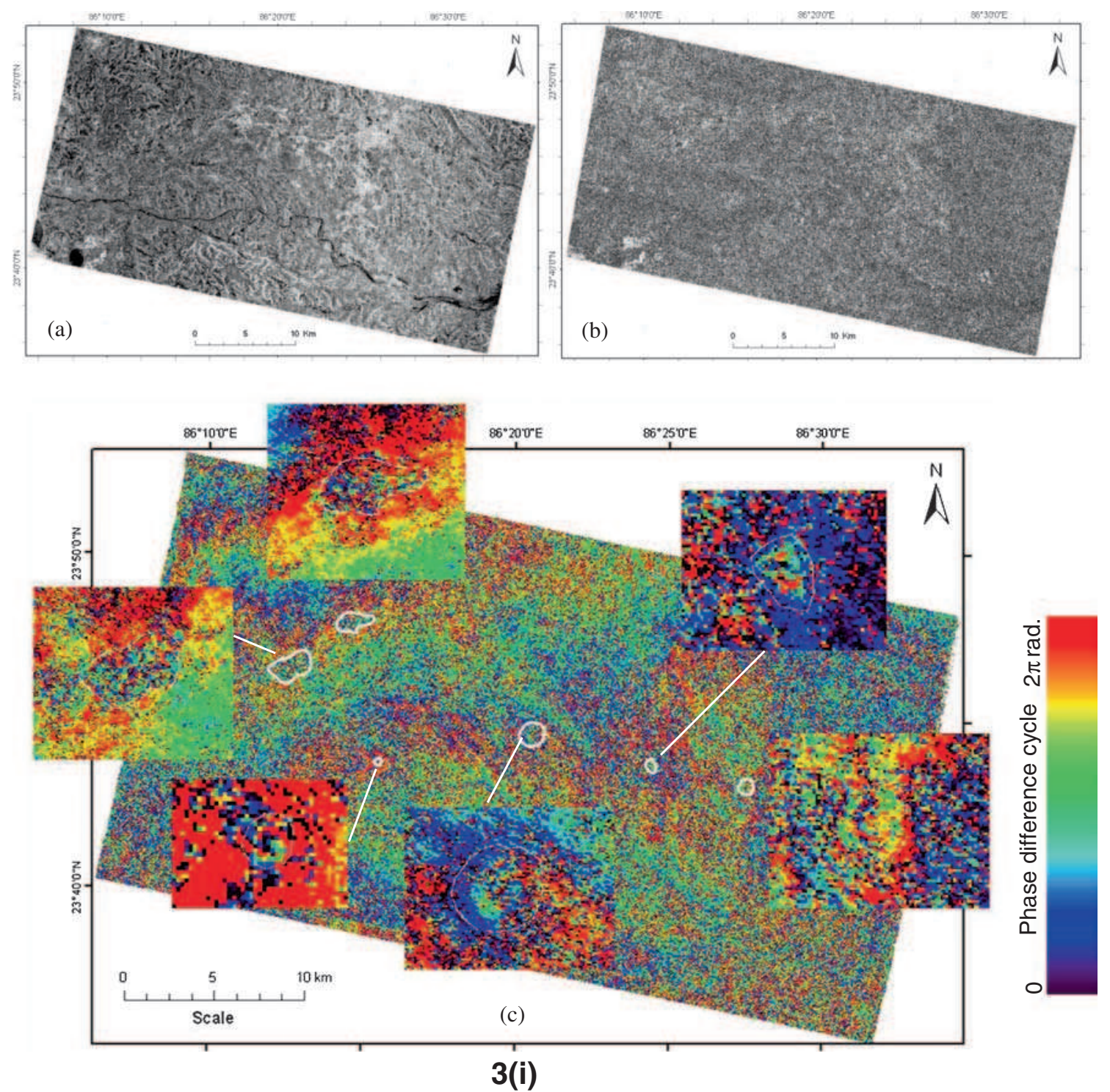

Figure 3. Differential interferometric SAR processing products of C-band ENVISAT ASAR and L-band ALOS PALSAR data pairs. Calibrated amplitude images $\left(\sigma_{\mathrm{o}}\right)$ of the master scenes of C-band ENVISAT ASAR pair 'C9835-11338' (a) and L-band ALOS PALSAR pair 'C10118-11460' (d). Coherence images of the ENVISAT pair 'C9835-11338' (b) and ALOS pair 'C10118-11460' (e). Post processed C- and L-band differential interferograms of ENVISAT (C9835-11338) and ALOS (C10118-11460) data pairs ('c' and 'f' respectively).

subsidence on the ground. Many of the newly detected subsidence areas were observed in C-band DInSAR perhaps due to its higher sensitivity to slow deformation than L-band DInSAR (figure 4). Many of them are located in and around the old and abandoned underground mine workings and/or coal fire areas that are not in general the areas of interest for the miners. For example, in the southwestern part of the coalfield to the south of NH32 National Highway segment between Mahuda Railway Station $\left(23^{\circ} 44^{\prime} 59^{\prime \prime} \mathrm{N}, 86^{\circ} 16^{\prime} 15.5^{\prime \prime} \mathrm{E}\right)$ and Telmuchu Bus Stop $\left(23^{\circ} 43^{\prime} 54.3^{\prime \prime} \mathrm{N}, 86^{\circ} 12^{\prime} 1.4^{\prime \prime} \mathrm{E}\right)$, three subsidence fringes were detected from C-band DInSAR during the observation period (2003-2004 and 2007). The subsidence fringes were observed in and around Haritola, Kanrra, Kalyanpur,
Simatanr and Madhudih villages $\left(23^{\circ} 43^{\prime} 51.6^{\prime \prime} \mathrm{N}\right.$, $86^{\circ} 13^{\prime} 44.4^{\prime \prime} \mathrm{E} ; 23^{\circ} 43^{\prime} 44.4^{\prime \prime} \mathrm{N}, 86^{\circ} 15^{\prime} 21.6^{\prime \prime} \mathrm{E} ; 23^{\circ} 44^{\prime} 6^{\prime \prime} \mathrm{N}$, $\left.86^{\circ} 15^{\prime} 46.8^{\prime \prime} \mathrm{E}\right)$. In and around the affected areas, we observed ground evidences of land subsidence like cracks in houses, land surface cracks and differential subsidence of terrain. The subsidence fringes are located in and around the old and abandoned underground mine workings. Similarly, we identified a broad subsidence fringe in Moonidih colliery area in the central part of the coalfield $\left(23^{\circ} 44^{\prime} 38.4^{\prime \prime} \mathrm{N}\right.$, $86^{\circ} 20^{\prime} 27.6^{\prime \prime} \mathrm{E}$ ), where longwall mining has been carried out for last few decades. However, because mining had been taking place at a deeper level (550-600 m), the rate of subsidence was relatively slow and the area was not reported by the mining agency. Similarly, from L-band DInSAR, a 

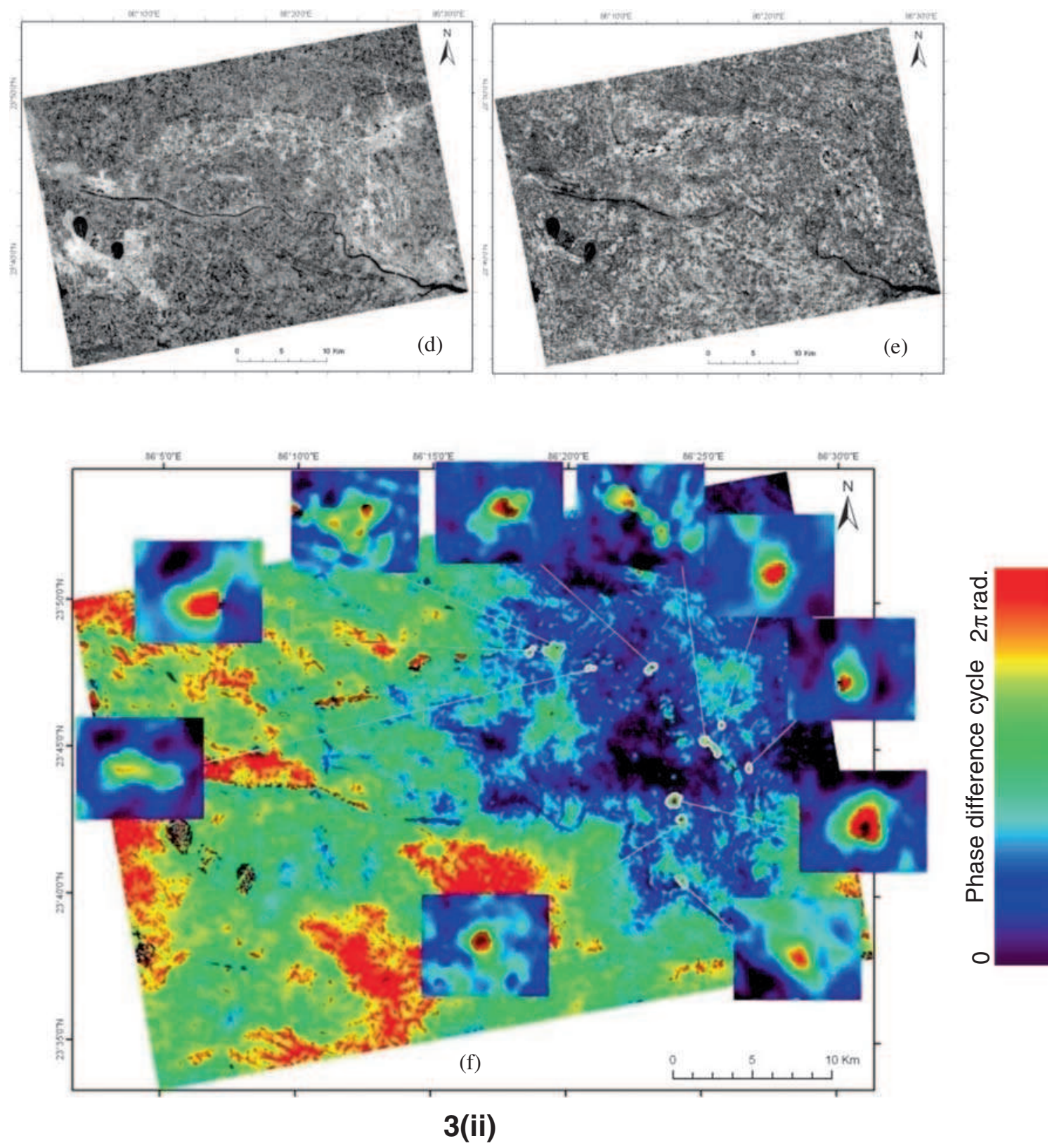

Figure 3. (Continued.)

couple of new unreported subsidence areas were detected. For example, the areas south of Bhowra $\left(23^{\circ} 40^{\prime} 22.8^{\prime \prime} \mathrm{N}, 86^{\circ} 24^{\prime} 14.4^{\prime \prime} \mathrm{E}\right)$, south of Bhelatanr $\left(23^{\circ} 46^{\prime} 8.4^{\prime \prime} \mathrm{N}, 86^{\circ} 19^{\prime} 22.8^{\prime \prime} \mathrm{E}\right)$, and south of Basuriya $\left(23^{\circ} 47^{\prime} 45.6^{\prime \prime} \mathrm{N}, 86^{\circ} 23^{\prime} 6^{\prime \prime} \mathrm{E}\right)$ villages were identified as subsidence areas in L-band DInSAR (figure 5). The newly detected subsidence areas were confirmed in the field and reported to the mining agencies.

From C-band DInSAR, we observed that 20.6 $\mathrm{km}^{2}$ area during 2003-2004 and $22.8 \mathrm{~km}^{2}$ area during 2007 were affected by land subsidence. We delineated a total area of $35.6 \mathrm{~km}^{2}$ affected by land subsidence during 2003-2004 and 2007 together (figure 4). Out of which, $7.9 \mathrm{~km}^{2}$ area had been consistently subsiding during 2003, 2004 and 2007, whereas another 12.7 and $14.9 \mathrm{~km}^{2}$ areas were affected by land subsidence respectively in 20032004 and 2007 alone. The result reflects spatio-temporal dynamics of land subsidence and their causes.

This is to note that during 2007-2008, we have both C- and L-band DInSAR observations. C-band ENVISAT ASAR observation period (approximately 5 months during March-May 2007 and October-December 2007) overlaps with L-band ALOS PALSAR observation period (approximately 14 months; during January 2007-March 2008). In this study, collateral observations by DInSAR, GPS and precision levelling were conducted. We also have the spatial extent of land subsidence during 2006-2008 based on groundsurveying as available from the mining agencies. 


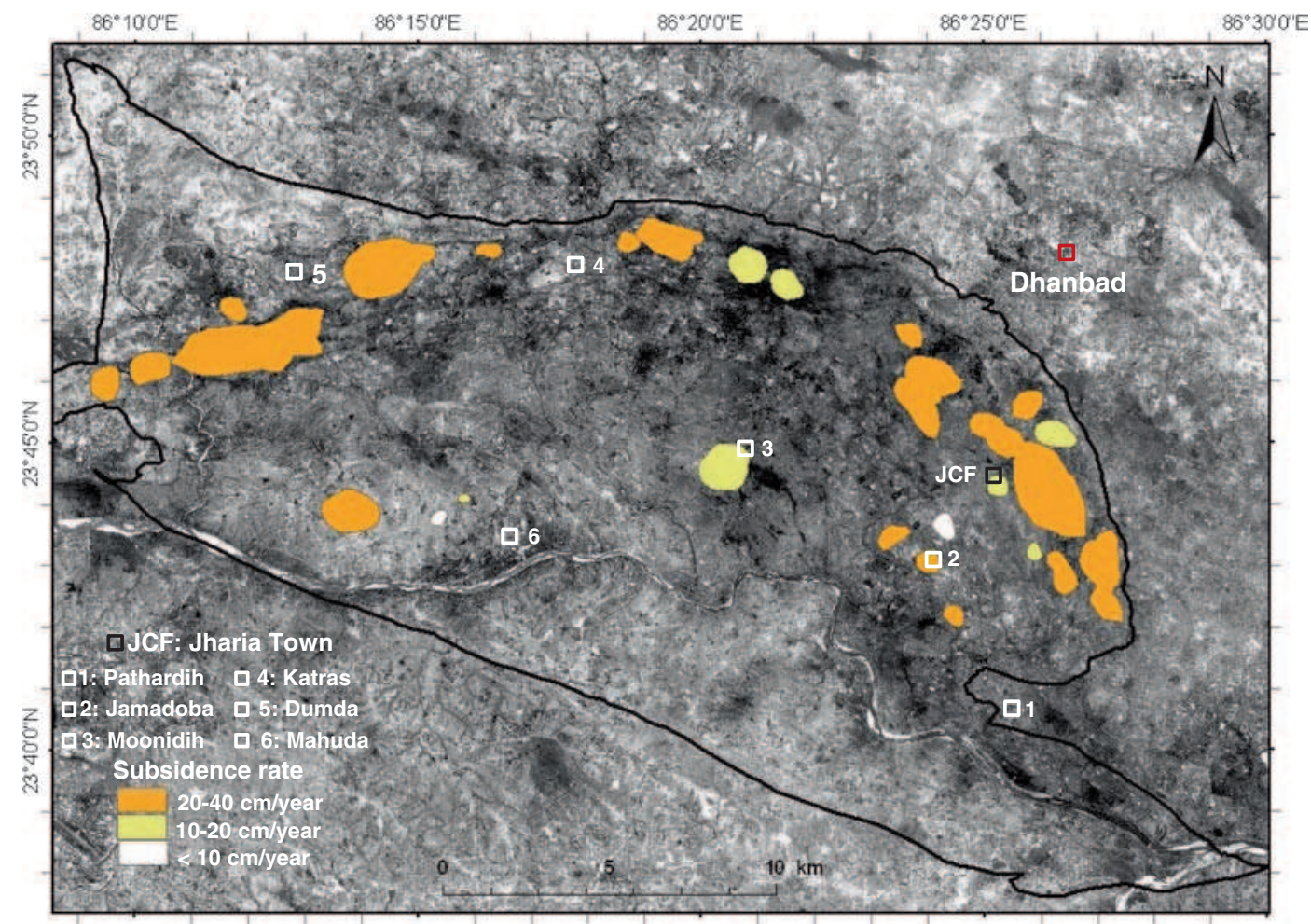

Figure 4. Land subsidence areas in Jharia Coalfield as obtained from C-band DInSAR of 2003-2004 and 2007 by union of the deformation fringes. High resolution IRS PAN image is used as background for localization of subsidence affected areas. Outline of Jharia Coal Basin is shown by solid black line.

We compared land subsidence results obtained from multi-frequency DInSAR and other collateral techniques conducted during 2006-2008. From C-band DInSAR, we detected $22.8 \mathrm{~km}^{2}$ land subsidence area during 2007 (figure 5a). In most of the subsidence affected areas, the maximum LOS subsidence rates were found to be in the range of 10-30 cm/year (figure 5c). On the other hand, from L-band DInSAR, we detected $12.2 \mathrm{~km}^{2}$ land subsidence area during 2007-2008 (figure 5b) with the maximum LOS subsidence rate going up to $55-60 \mathrm{~cm} /$ year (figure $5 \mathrm{~d}$ ). Out of this, in $4.4 \mathrm{~km}^{2}$ area, land subsidence was observed in both $\mathrm{C}$ - and L-band DInSAR. On the other hand, in $7.8 \mathrm{~km}^{2}$ area, land subsidence was observed exclusively in L-band DInSAR and in $18.4 \mathrm{~km}^{2}$ area, land subsidence was observed only in C-band DInSAR (figure 6).

\subsection{Precision levelling results and analysis}

We conducted collateral observation by precision levelling and geodetic GPS survey in three test sites near Dobari, Joyrampur and East Basuriya collieries of Jharia Coalfield. Levelling survey was conducted four times during January 2007-June 2008. The average vertical displacement rates in Dobari, Joyrampur and East Basuriya test sites during the observation period are given in table 2 .
In Dobari test site, the rate of vertical displacement was very high as expected in case of depillaring by caving type of underground mining operations. Levelling observation was made during active mining phase as well as after the cessation of mining. It is established that almost $90 \%$ of the total subsidence occurs during active mining phase. In Joyrampur and East Basuriya test sites, the rate of vertical displacement was moderate to high. Subsidence occurred primarily due to subsurface coal fire. It is observed that the rate of subsidence was much higher in caving panel compared to that occurring due to coal fire. Additionally, vulnerable old and abandoned underground mine workings sometimes cause land subsidence.

\subsection{GPS observation results and analysis}

In GPS survey, $\mathrm{X}-\mathrm{Y}$ coordinates of the monuments were precisely measured. For two successive observations, the changes in $\mathrm{X}$ - and $\mathrm{Y}$-coordinates were calculated for each of the monuments. From the changes in $\mathrm{X}$ - and $\mathrm{Y}$-coordinates $(\Delta x$ and $\Delta y)$, the net horizontal displacement during the observation period was calculated as $D_{i}=\sqrt{\Delta x_{i}^{2}+\Delta y_{i}^{2}}$, where $D_{i}$ represents the horizontal displacement at monument ' $i$ ' during the given observation period. From the initial and final locations of the monuments, the azimuths of the displacement vectors 

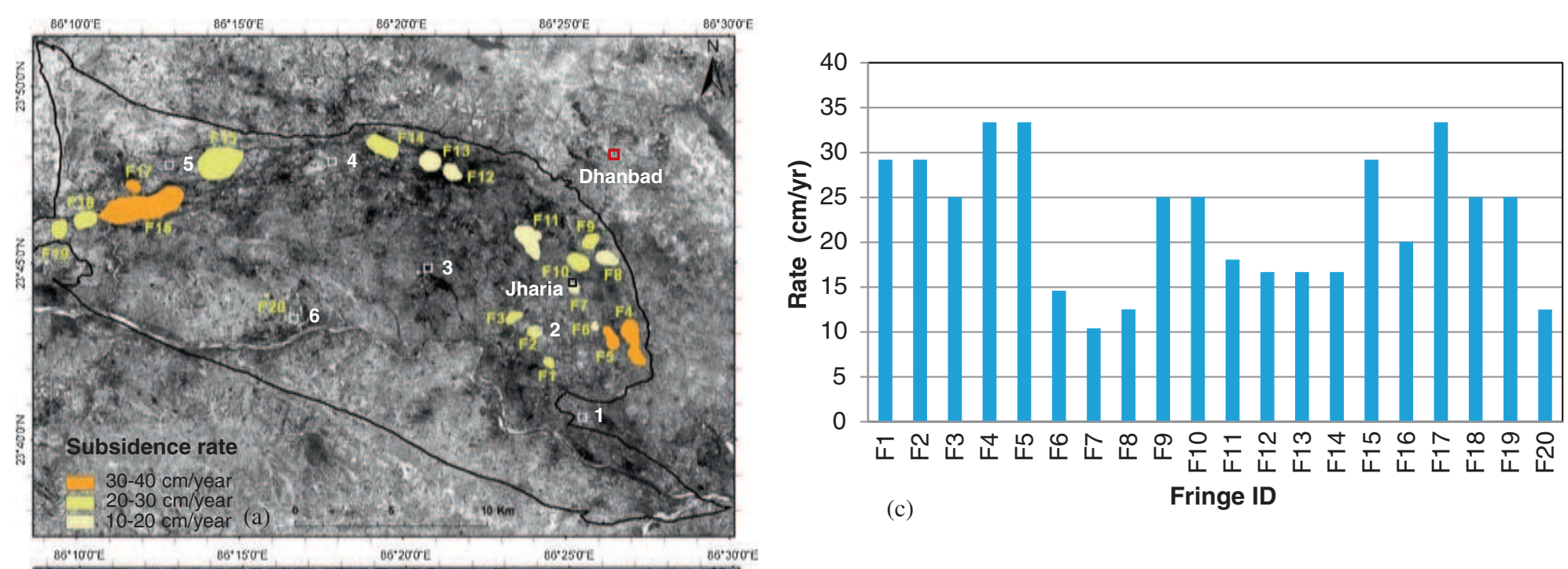

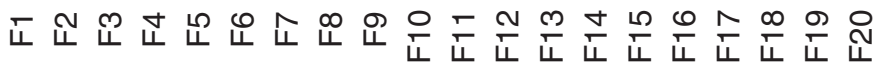

(c)

Fringe ID
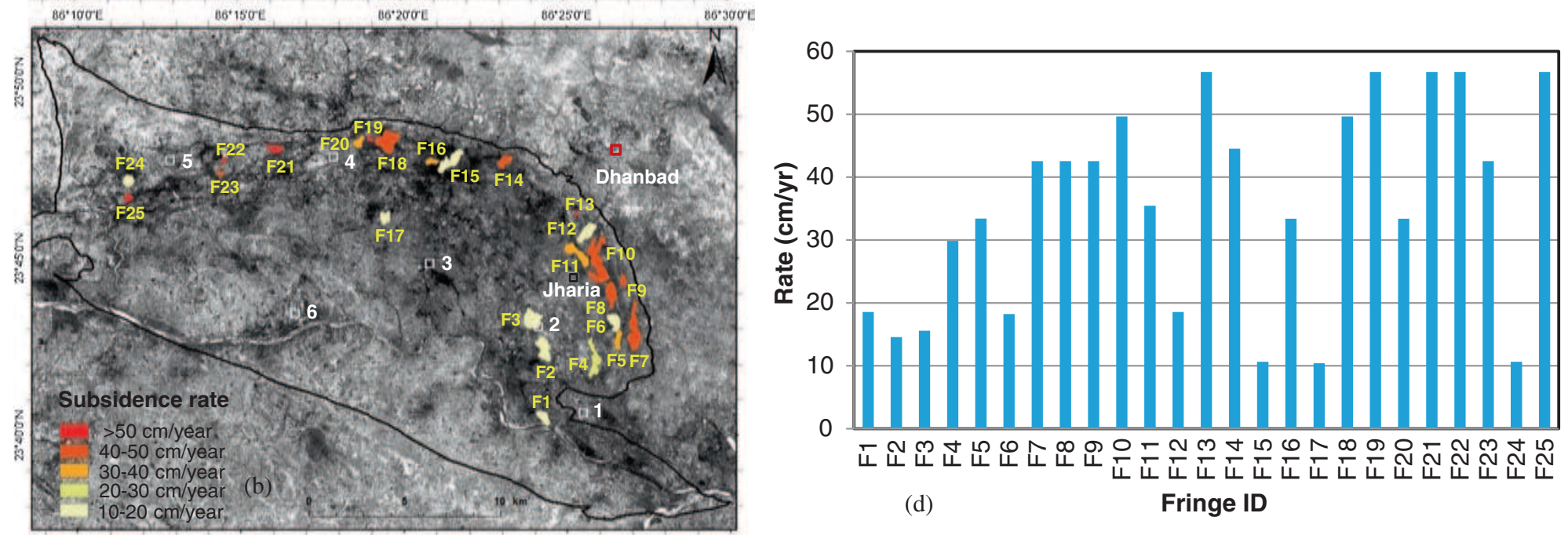

Name of the localities' marked by 1, 2, 3, 4, 5, 6 are given in previous figures

(d)

Fringe ID

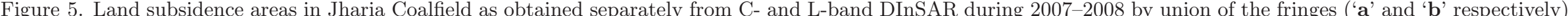

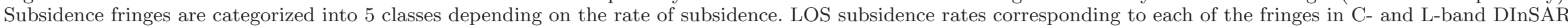

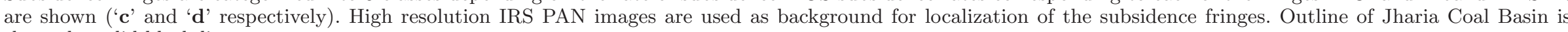
shown by solid black line. 


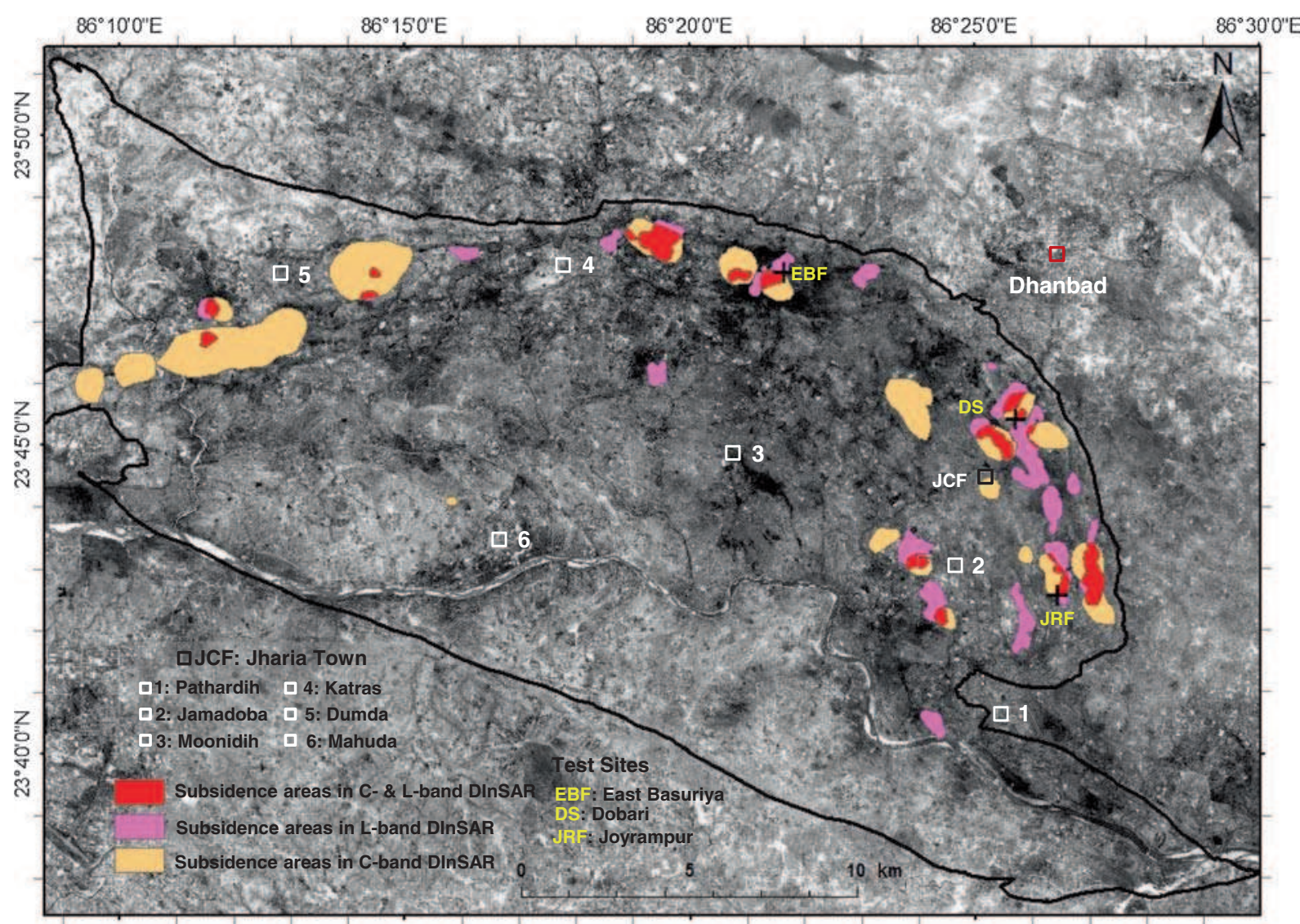

Figure 6. Combined land subsidence areas in Jharia Coalfield as obtained from C- and L-band DInSAR together during 2007-2008. The locations of the test sites for ground-based observations are shown by plus signs. High resolution IRS PAN image is used as background for localization of the subsidence fringes. Outline of Jharia Coal Basin is shown by solid black line.

were determined. For each test site, the angular distribution of the displacement vectors was plotted (figure 7a) and the vector mean orientation $(\widehat{\gamma})$ was calculated as $\widehat{\gamma}=\tan ^{-1}(W / V)$, where $W$ and $V$ are respectively the sums of sines and cosines of displacement directions within each sector. The average horizontal displacement rates in three test sites during the observation period are given in table 2 . The horizontal displacement vectors are directed towards $287^{\circ}, 211^{\circ}$ and $138^{\circ}$ respectively in Dobari, Joyrampur and East Basuriya test sites.

\subsection{Net displacement vectors}

As described before (in section 4.3), the azimuth of the net displacement vectors in three test sites was determined from multi-temporal GPS observations. Subsequently, using the mean vertical $(V)$ and mean horizontal $(H)$ displacement components obtained from precision levelling and GPS measurements, the magnitude and inclination angle of the net displacement vectors were determined. We determined the magnitude of the net displacement vector as $\sqrt{H^{2}+V^{2}}$, whereas the inclination angle with respect to the horizontal plane as $\tan ^{-1}(V / H)$. Finally, we obtained the magnitude and 3-dimensional orientation of the net displacement vectors in Dobari, Joyrampur and East Basuriya test sites as $85.1,34.4$ and $18.8 \mathrm{~cm} /$ year, respectively, with orientations $80.1^{\circ} \rightarrow 287^{\circ}, 72.9^{\circ} \rightarrow 211^{\circ}$ and $61.7^{\circ} \rightarrow 138^{\circ}$ (figure $7 \mathrm{~b}$ ).

\subsection{Comparison of subsidence rates}

In this section, we compared land subsidence rates in three test sites obtained from spaceborne DInSAR, and ground-based precision levelling and GPS observations. DInSAR observation periods (5 months for C-band during March-May 2007 and October-December 2007, and 14 months for Lband during January 2007-March 2008) overlap with levelling (18 months during January 2007June 2008) and GPS observations (24 months during July 2006-June 2008) periods. Coherence weighed DInSAR LOS subsidence rates of three test sites were compared with radar LOS projected ground-based measurements. For this purpose, we projected GPS-based horizontal displacement vectors of three test sites into radar LOS directions of ENVISAT ASAR and ALOS PALSAR. Using the 
Table 2. Spaceborne DInSAR, Ground-based precision levelling and GPS observations in Dobari, Joyrampur and East Basuriya test sites during the observation period.

\begin{tabular}{|c|c|c|c|c|}
\hline \multirow[b]{2}{*}{ Test site } & \multicolumn{2}{|c|}{ Spaceborne observation } & \multicolumn{2}{|c|}{ Ground-based observation } \\
\hline & $\begin{array}{l}\text { ENVISAT ASAR } \\
\text { C-band DInSAR } \\
\text { LOS subsidence } \\
\text { rate }(\mathrm{cm} / \text { year })\end{array}$ & $\begin{array}{c}\text { ALOS PALSAR } \\
\text { L-band DInSAR } \\
\text { LOS subsidence } \\
\text { rate }(\mathrm{cm} / \text { year })\end{array}$ & $\begin{array}{l}\text { Average vertical } \\
\text { displacement rate } \\
\text { by precision } \\
\text { levelling }(\mathrm{cm} / \text { year })\end{array}$ & $\begin{array}{l}\text { Average horizontal } \\
\text { displacement rate } \\
\text { by GPS }(\mathrm{cm} / \text { year })\end{array}$ \\
\hline Dobari & 37.3 & 46.0 & $82.7(\mathrm{n}=16)$ & $20.2(\mathrm{n}=10)$ \\
\hline Joyrampur & 30.7 & 24.1 & $33.1(\mathrm{n}=7)$ & $9.2(\mathrm{n}=7)$ \\
\hline East Basuriya & 14.8 & 17.9 & $16.6(\mathrm{n}=7)$ & $8.9(\mathrm{n}=7)$ \\
\hline
\end{tabular}

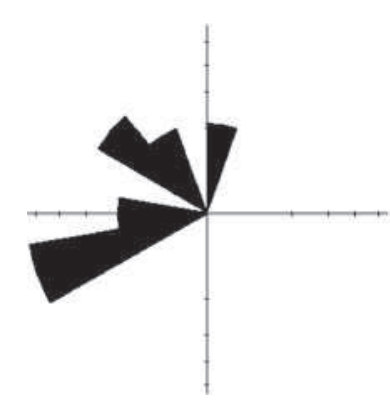

Mean resultant direction $=287^{\circ}$ Circular mean deviation $=37^{\circ}$ Sector interval $=20^{\circ}$

(i)

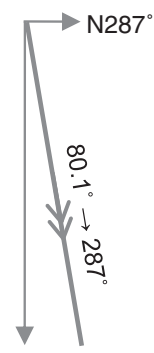

(i)

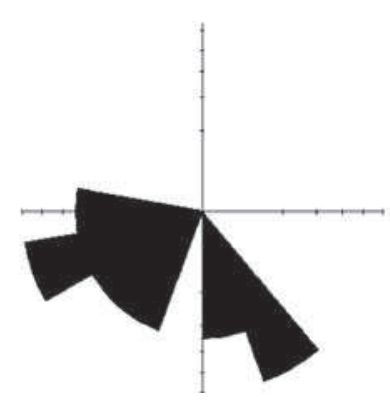

Mean resultant direction $=211^{\circ}$ Circular mean deviation $=42^{\circ}$ Sector interval $=20^{\circ}$

(ii)

(a)

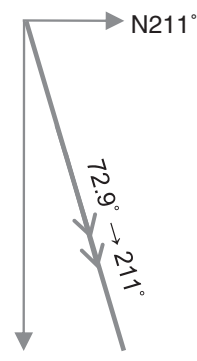

(ii)

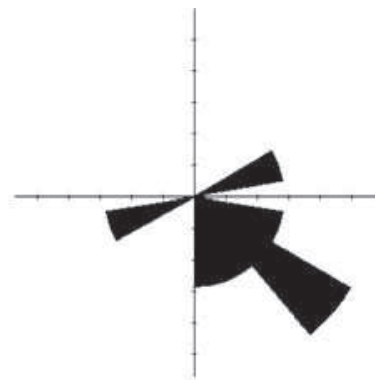

Mean resultant direction $=138^{\circ}$ Circular mean deviation $=38^{\circ}$ Sector interval $=20^{\circ}$

(iii)

(Displacement magnitudes are not to scale; horizontal : vertical relative scale is maintained)

(b)

Figure 7. (a) Angular distribution of GPS based horizontal displacement vectors at the monuments in three test sites during 2006-2008: Dobari (i), Joyrampur (ii) and East Basuriya (iii). (b) Orientation of the ground-based net displacement vectors in three test sites during the observation period: Dobari (i), Joyrampur (ii) and East Basuriya (iii).

projected horizontal displacement vectors and the vertical displacement vectors obtained respectively from GPS and precision levelling measurements, we determined radar LOS projected displacement vectors for the three test sites.

We find that except for C-band observation in Dobari test site, coherence weighed DInSAR LOS subsidence rates show fairly good agreement with ground-based measurements (figure 8). In case of C-band, DInSAR LOS subsidence rates are respectively 37.3, 30.7 and $14.8 \mathrm{~cm} /$ year in Dobari,
Joyrampur and East Basuriya test sites, whereas radar LOS projected ground-based subsidence rates are 83.4, 32.6 and $13.2 \mathrm{~cm} /$ year respectively. Similarly, in case of L-band, DInSAR LOS subsidence rates are 46.0, 24.1 and $17.7 \mathrm{~cm} /$ year in Dobari, Joyrampur and East Basuriya test sites, and radar LOS projected ground-based subsidence rates are 54.0, 20.9 and $16.2 \mathrm{~cm} /$ year respectively. From ground-based measurements, we also observed that in addition to a dominantly vertical component, there was an appreciable horizontal 


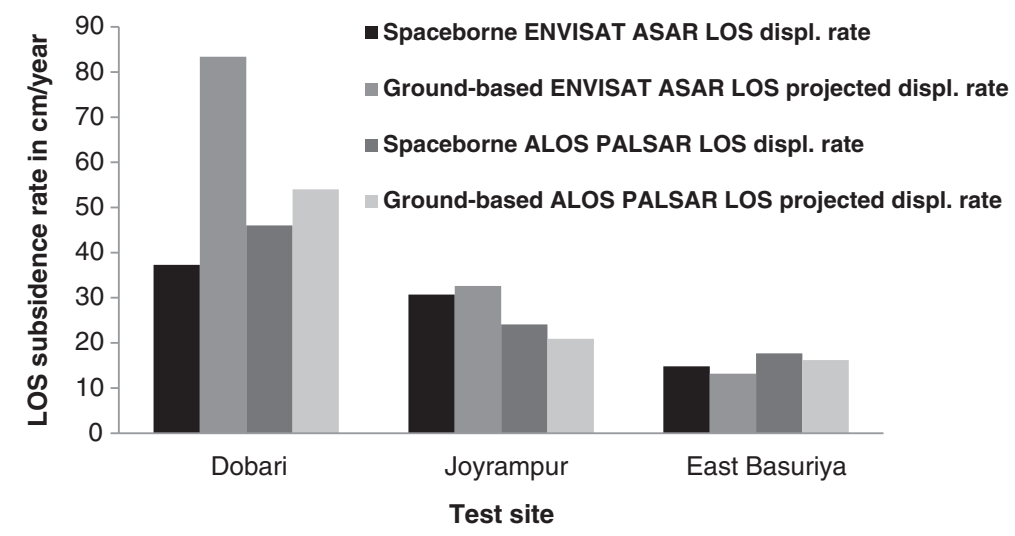

Figure 8. Comparison of spaceborne DInSAR and ground-based subsidence rates in Dobari, Joyrampur and East Basuriya test sites of the study area: spaceborne ENVISAT ASAR LOS DInSAR displacement rate vs. ENVISAT ASAR LOS projected ground-based displacement rate and spaceborne ALOS PALSAR LOS DInSAR displacement rate vs. ALOS PALSAR LOS projected ground-based displacement rate.

displacement component of land subsidence. The horizontal displacement was the maximum in case of Dobari test site followed by Joyrampur and East Basuriya.

\subsection{Discussion}

In general, slowly to moderately subsiding areas were detected well from C-band DInSAR, whereas rapidly subsiding areas were detected from Lband DInSAR. In fact, the precision of DInSAR and its detectability of land surface displacement are essentially governed by the radar wavelength. Ideally, land surface displacement up to a small fraction $(1 / 20-1 / 40)$ of the radar wavelength can be detected by DInSAR. DInSAR detectability of land surface displacement and the quality of measurement are also governed by the magnitude of displacement and the spatial extent over which it occurs. The condition for interferometry implies that the maximum detectable deformation gradient is one fringe per pixel or the dimensionless ratio of the pixel size to the radar wavelength (Massonnet and Feigl 1998). In the study area, the deformation fringes are smaller in spatial extent and spatially scattered. Also, the rate of subsidence varies widely from a few $\mathrm{cm}$ to tens of $\mathrm{cm}$ per year. We observed a fairly good agreement between spaceborne DInSAR and ground-based measurements in all the cases except for C-band DInSAR observation in Dobari test site. In case of high magnitude displacement occurring over a smaller spatial extent like Dobari test site, it is likely that the deformation gradient exceeds the limit in central pixels in case of shorter wavelength C-band DInSAR. This gives rise to phase decorrelation of the central pixels and degradation of DInSAR quality which was also reported by Yue et al. (2011). For such areas with high magnitude displacement, the detectability of land surface displacement and the quality of measurements are much higher in longer wavelength L-band DInSAR.

To address the discrepancy between spaceborne DInSAR and ground-based measurements in the test sites, we analyzed the following factors:

(i) the phase quality in DInSAR measurement,

(ii) the subsidence monitoring monuments used for precision levelling and GPS survey and their location with respect to the deformation fringes,

(iii) the magnitude of horizontal displacement and LOS of the radar beam, and

(iv) the difference in observation periods of collateral techniques particularly in areas of temporally inconsistent subsidence.

The quality of DInSAR phase in the individual differential interferograms is utmost important to determine DInSAR-based average subsidence rates in the test sites for comparison of results. This is essentially controlled by InSAR coherence of the respective data pairs. We adopted a coherence weighed algorithm taking into account the contribution of each data pair as a function of average InSAR coherence over the test site.

The spatial extent of the test sites was confined to less than $500 \mathrm{~m}$ diameter area. All the areas were spatially overlapping with the deformation fringes. The monuments were spatially distributed in different parts of the deformation fringes. The same set of monuments was used for precision levelling and GPS observations. A couple of monuments were however lost during individual survey due to adverse land cover which may add subtle discrepancy between DInSAR and ground-based measurements. 

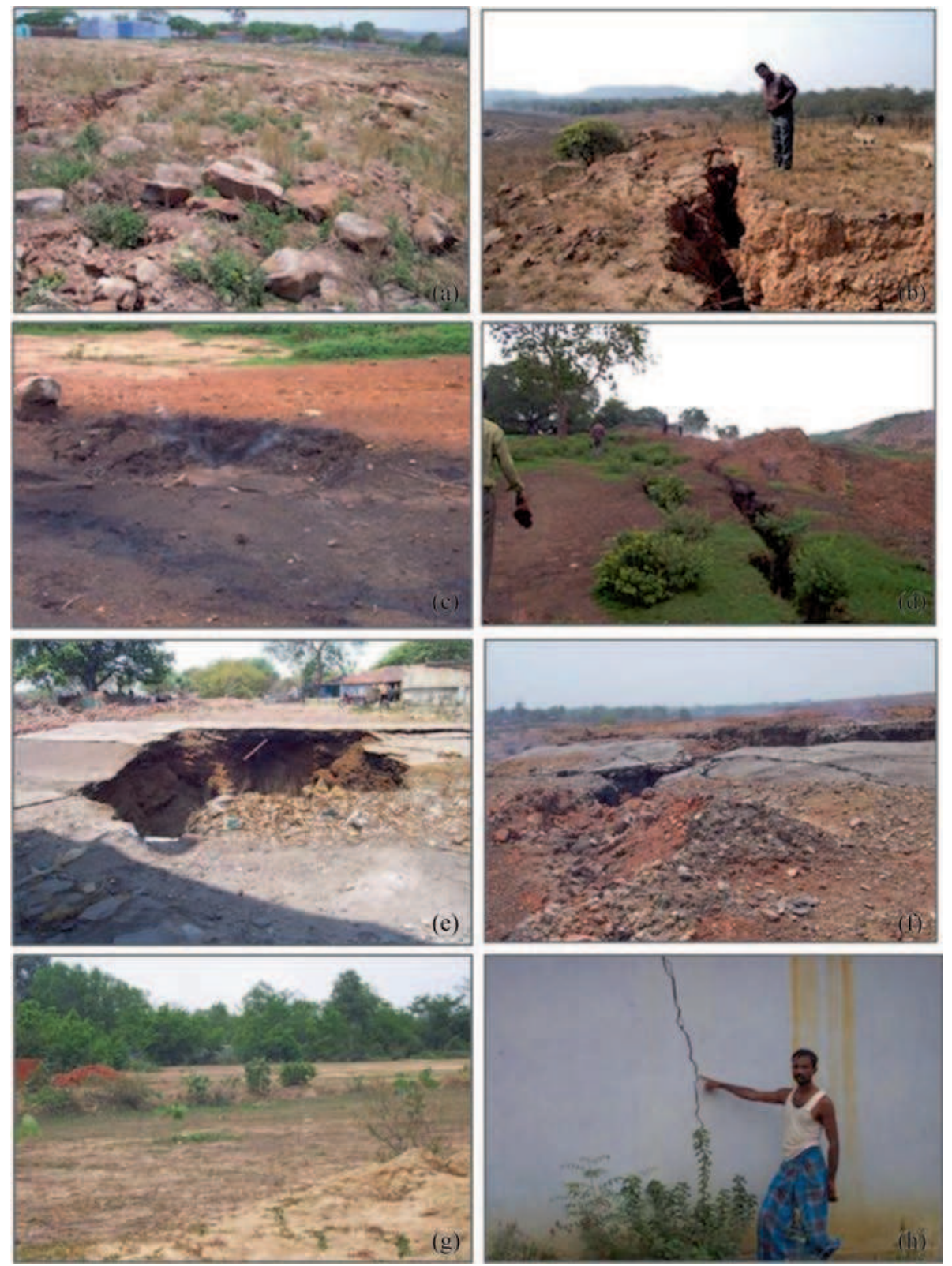

Figure 9. Field photographs showing evidence and severity of land subsidence in the test sites ('a' and 'b' in Dobari, 'c' in Joyrampur and ' $\mathbf{d}$ ' in East Basuriya test sites) and nearby areas ('e' in Kusunda and 'f' in Lodna collieries). Roof collapse and wide surface fissures killed lives and damaged infrastructures ('e' and 'f' respectively). Evidences of land subsidence with terrain cracks, terrain elevation modification and profuse cracks in concrete walls of the houses (' $\mathrm{g}$ ' and ' $\mathbf{h}$ ') in previously unreported areas.

During the observation period, the horizontal displacement rate was the maximum in Dobari test site $(20.2 \mathrm{~cm} /$ year $)$ followed by Joyrampur $(9.2$ $\mathrm{cm} /$ year $)$ and East Basuriya $(8.9 \mathrm{~cm} /$ year $)$ test sites. Also, the horizontal displacement component was projected differently in relation to the radar LOS directions in ENVISAT ASAR and ALOS PALSAR data pairs which contributed to the discrepancy between DInSAR and ground-based measurements. In a word, a large horizontal displacement component in Dobari test site (the largest among the three test sites) and steeper incidence angle in $\mathrm{C}$-band DInSAR $\left(23^{\circ}\right)$ contributed to a larger difference.
In Dobari test site, land subsidence occurred due to depillaring by caving type of underground mining operations. On the other hand, in Joyrampur and East Basuriya test sites, land subsidence occurred primarily due to coal fire. As per survey record of the mining agency (BCCL, Coal India Ltd.) and field survey, surface and subsurface coal fires remained more or less consistent in Joyrampur and East Basuriya test sites during 2006-2008, which therefore produced temporally consistent subsidence during the observation period. But, in Dobari test site, mininginduced subsidence was characterized by spatial and temporal variability in mining operations 
(depillaring by caving operations), rate of mining and geotechnical properties of overburden strata. As a result, it produced temporally inconsistent subsidence rates. In Dobari test site, underground mining operation took place during February 2006November 2007. C-band DInSAR covers only 4 months (March-May 2007 and October-December 2007) of the active subsidence phase out of the total 21 months of underground mining operation and approximately one month of post-mining residual subsidence phase. Whereas, L-band DInSAR (January 2007-March 2008) covers 11 months of active subsidence phase and 4 months of postmining residual subsidence phase. On the other hand, ground-based observation by precision levelling (January 2007-June 2008) covers 11 months of active subsidence phase (same as L-band DInSAR) and 7 months of post-mining residual subsidence phase. Similarly, ground-based GPS observation (July 2006-June 2008) covers 17 months of active subsidence phase and 7 months of post-mining residual subsidence phase.

It may be noted that in Joyrampur and East Basuriya test sites, as the subsidence rates are temporally consistent, the difference in the duration of observation periods between DInSAR and ground-based techniques did not contribute significantly to the differences in the subsidence rates. We observed that the subsidence rates obtained from C- and L-band DInSAR agree fairly well with ground-based subsidence rates. On the other hand, in Dobari test site, as the subsidence rates are temporally inconsistent, the observation periods should have been closely similar for comparison of results. The observation periods of L-band DInSAR (January 2007-March 2008) and ground-based precision levelling (January 2007June 2008) are closely similar. And, we found a fairly good agreement between L-band DInSAR and ground-based measurements. A little extended GPS observation period (July-December 2006 and April-June 2008) did not appreciably contribute to the discrepancy as the horizontal displacement component was only $1 / 5$ th of the vertical displacement component. On the other hand, the observation period of C-band DInSAR was markedly less compared to ground-based observation periods. It has only 5 months observation period (March-May 2007 and October-December 2007) overlapping with 18 months precision levelling (January 2007-June 2008) and 24 months GPS (July 2006-June 2008) observations. A large difference in the duration of observation periods during mining induced temporally inconsistent active subsidence phase contributed immensely to the difference in the subsidence rates. To give some glimpses of land subsidence in the coalfield, a couple of field photographs showing the evidences and severity of land subsidence in the test sites and nearby areas were included (figure 9a-f). Some field photographs showing ground evidences of subsidence in previously unreported land subsidence areas were also included (figure $9 \mathrm{~g}-\mathrm{h}$ ).

\section{Conclusions}

Using multi-frequency C- and L-band DInSAR, we could delineate both slowly and rapidly subsiding areas in the coalfield. By DInSAR data analysis, we found several new subsidence areas. Many of them are located, in and around, old and abandoned underground mine workings and/or coal fire affected areas. We compared spaceborne DInSAR measurements with ground-based precision levelling and GPS observations in three test sites. We found a difference of $(-) 54.8 \%,(-) 5.8 \%$ and $(+)$ $12.1 \%$ in C-band DInSAR, and $(-) 14.8 \%,(+)$ $15.3 \%$ and $(+) 9.3 \%$ in L-band DInSAR respectively for Dobari, Joyrampur and East Basuriya test sites.

In Joyrampur and East Basuriya test sites, we observed that both C- and L-band DInSAR subsidence rates agree well with ground-based measurements. In Dobari test site, L-band DInSAR subsidence rate agrees well with groundbased subsidence rate. But, the difference between C-band DInSAR and ground-based subsidence rates was significantly large. This can be primarily attributed to a large difference between DInSAR and ground-based observation periods and temporally inconsistent land subsidence. A possible temporal decorrelation in the fringe centres due to high deformation gradient and a large horizontal displacement component may be considered other plausible reasons for the discrepancy between C-band DInSAR and ground-based subsidence rates in Dobari test site.

It may be concluded that the adopted methodology can be used successfully for detection, mapping and monitoring of subsiding areas vulnerable to roof collapse, determination of net displacement vectors and horizontal displacement components in the affected coal mining areas like Jharia Coalfield where the causes of subsidence are complex, spatially varied and temporally irregular. This will facilitate efficient planning and designing of surface infrastructures and other developmental structures in the mining areas. Precise information on the spatial extent of subsiding areas, rate and nature of subsidence may help in identifying the areas prone to roof collapse and in recommending probable mitigation measures for subsidence induced hazards. The methodology can also be used for other coalfields located in India or other parts of the world with similar kind of land subsidence problems. 


\section{Acknowledgements}

The study was carried out under JEP-Microwave and RISAT-UP Projects of Indian Space Research Organization (ISRO), Dept. of Space, India. The authors gratefully acknowledge Director and Dean, Indian Institute of Remote Sensing (IIRS), Dehradun, India; Director, Central Institute of Mining and Fuel Research (CIMFR), Dhanbad, India; Director, Geodetic and Research Branch, Survey of India, Dehradun, India and Director (Technical Operations), Bharat Coking Coal Ltd (BCCL), Dhanbad, India for their guidance and support. The authors are immensely grateful to Dr Amar Prakash, Sr. Scientist, CIMFR, Dhanbad, India, Dr I C Das, Sr Scientist, IIRS and Dr P K Champati Ray, Head Geosciences and Geohazards Dept., IIRS, Dehradun, India for technical guidance, suggestions and help during the execution of the project. The authors also sincerely thank and acknowledge the help and services provided by Mr. S N Rajak and Mr. B Paswan of CIMFR, Dhanbad, India, Mr. R K Shahi, Mr. Prabal Dutta and Mr. B S Rawat of Survey of India, Dehradun, India and Mr. P D Sharma of BCCL, Dhanbad, India. The authors gratefully acknowledge Mr. Ritwik Majumdar, Md Ali Akbar, Ms. Suranjana B Borah, Moh. Fifik Syafiudin, Ms. Arpita Sinha and Mr. Asit B Mahato, students and researchers, IIRS, Dehradun, India for their contributions in ground survey and field data collection. The authors convey their sincere gratitude to the staff and officials of the mining agencies namely, BCCL, Tata Steel and Steel Authority of India Ltd (SAIL), Dhanbad, India for their help and cooperation during ground survey.

\section{References}

Acharyya S K 2000 Coal and lignite resources of India an overview; H S Pareek special lecture delivered at Bhopal on 9 December 1999, Geological Society of India, Bangalore, 50p.

Ashrafianfar N, Hebel H-P and Busch W 2011 Monitoring of mining induced land subsidence - differential SAR interferometry and persistent scatterer interferometry using Terra SAR-X data in comparison with ENVISAT data; 4th Terra SAR-X Science Team Meeting, 14-16 February 2011, DLR, Oberpfaffenhofen, 7p.

Cao L, Zhang Y, He J, Liu G, Yue H, Wang R and Ge L 2008 Coal mine land subsidence monitoring by using spaceborne InSAR data - A case study in Fengfeng, Hebei Province, China; The International Archives of the Photogrammetry; Remote Sens. Spatial Infor. Sci. XXXVII-B8 255-261.

Census of India 2001 Office of the Registrar General, India, 2A Mansingh Road, New Delhi, July 2001.

Chatterjee R S 2006 Coal fire mapping from satellite thermal IR data - A case example in Jharia Coalfield, Jharkhand, India; ISPRS J. Photogram. Remote Sens. 60 $113-128$.
Chatterjee R S 2009 Land subsidence phenomena: Recent developments in terrestrial and space-borne measurement techniques and modeling; In: Geoinformatics for Natural Resource Management (eds) Joshi P K et al., New York, Nova Science Publishers, pp. 383-407.

Chatterjee R S, Fruneau B, Rudant J P, Roy P S, Frison P L, Lakhera R C, Dadhwal V K and Saha R 2006 Subsidence of Kolkata (Calcutta) City, India during the 1990s as observed from space by differential synthetic aperture radar interferometry (DInSAR) technique; Remote Sens. Environ. 102 176-185.

Engelbrecht J, Inggs M R and Makusha G 2011 Detection and monitoring of surface subsidence associated with mining activities in the Witbank Coalfields, South Africa, using differential radar interferometry; South African J. Geol. 114(1) 77-94.

Ge L, Chang H and Rizos C 2007 Mine subsidence monitoring using multi-source satellite SAR images; Photogram. Eng. Remote Sens. 73(3) 259-266.

Goldstein R and Werner C 1998 Radar interferogram filtering for geophysical application; Geophys. Res. Lett. 25(21) 4035-4038.

Gong Y 2011 Mining subsidence monitoring using ALOS satellite data; In: Proceedings of Geoinformatics 2011, $19^{\text {th }}$ International Conference, Shanghai, China, 24-26 June 2011, 3p.

Leick A 2004 GPS satellite surveying; 3rd edn, John Wiley and Sons, New York.

Liu G, Guo H, Fan J, Guo X, Perski Z and Yue H 2009 Mining area subsidence monitoring using multi-band SAR data; In: Proceedings of Urban Remote Sensing Event, Shanghai, China, 20-22 May 2009, 6p.

Lokhande R D, Prakash A and Singh K B 2008 Validation of predicted subsidence movements for a stowed panel; Minetech 29(3) 21-27.

Massonnet D and Feigl K L 1998 Radar interferometry and its applications to changes in the earth surface; Rev. Geophys. 36(4) 441-500.

Mukherjee T K, Bandyopadhyay T K and Pande S K 1991 Detection and delineation of depth of subsurface coalmine fires based on an airborne multispectral scanner survey in a part of the Jharia Coalfiled, India; Photogram. Eng. Remote Sens. 57(9) 1203-1207.

Nakamura R, Nakamura S, Kudo N and Katagiri S 2007 Precise orbit determination for ALOS, NASA Technical Documents, Document ID: 20080012666.

Perski Z 1998 Applicability of ERS-1 and ERS-2 InSAR for land subsidence monitoring in the Silesian coal mining region, Poland; Int. Arch. Photogram. Remote Sens. 32(7) 555-558.

Perski Z 2000 The interpretation of ERS-1 and ERS-2 InSAR data for the mining subsidence monitoring in upper Silesian coal basin, Poland; Int. Arch. Photogram. Remote Sens. 33(B7) 1137-1141.

Perski Z and Jura D 2003 Identification and measurement of mining subsidence with SAR interferometry: Potentials and limitations; In: Proceedings of 11th FIG Symposium on Deformation Measurements, Santorini, Greece, 2003, 7p.

Stow R and Wright P 1997 Mining subsidence land survey by SAR interferometry. In: Proceedings of 3rd Symposium on Space at the service of our Environment, Florence, Italy, 17-21 March 1997, pp. 525-530.

Strozzi T, Wegmüller U, Tosi L, Bitelli G and Spreckels V 2001 Land subsidence monitoring with differential SAR interferometry; Photogram. Eng. Remote Sens. 67(11) 1261-1270.

Tosi L, Teatini P, Carbognin L and Frankenfield J 2007 A new project to monitor land subsidence in the northern Venice coastland (Italy); Environ. Geol. 52(5) 889-898. 
Trimble 2007 Data sheet: Trimble DiNi Digital Level; http:// www.trimble.com/.

Walter D, Wegmüller U, Spreckels V, Hannemann W and Busch W 2009 Interferometric monitoring of an active underground mining field with high-resolution SAR sensors; In: Proceedings of ISPRS Hannover Workshop 2009 on high-resolution earth imaging for geospatial information, Hannover, Germany, 2-5 June 2009, XXXVIII-1-47/W5, 6p.

Wang Z, Liu G, Chen, Zhang J and Huang G 2010 Detecting and assessing the land subsidence in coal mining area using PALSAR data based on DInSAR technique. In: Proceedings of $2^{\text {nd }}$ International Conference on Computer Engineering and Technology (ICCET), Chengdu, China, 16-18 April 2010, V3, 222226.

Yue H, Liu G, Guo H, Li X, Kang Z, Wang R and Zhong X 2011 Coal mining induced land subsidence monitoring using multiband spaceborne differential interferometric synthetic aperture radar data; J. Appl. Remote Sens. 5(1) 53,518-53,529. 